\title{
Quality of intrapartum and newborn care in Tigray, Northern Ethiopia
}

Girmatsion Fisseha ${ }^{1 *}$, Yemane Berhane ${ }^{2}$ and Alemayehu Worku ${ }^{2,3}$

\begin{abstract}
Background: Quality intrapartum and newborn care is considered to be poor in Sub-Saharan Africa. However, studies done in Ethiopia are limited. Therefore, this study was conducted to assess the magnitude and factors associated with quality intrapartum and newborn care in Tigray, Northern Ethiopia.

Methods: Facility based survey was conducted from December 2014 to February 2015 in Tigray, Northern Ethiopia. The quality of intrapartum care provided by a total of 106 skilled birth attendants to 216 labouring mothers and newborns were observed during childbirth in the health facilities. Standardized questionnaires and checklist were utilized to collect data. Quality of intrapartum service was measured using standard intrapartum criteria. Thus, good quality service was considered if the mother and newborn scored $75 \%$ or more of the intrapartum criteria during childbirth. Binary and multiple logistic regression model was used to determine the factors associated with quality intrapartum and newborn care services.
\end{abstract}

Results: $29.2 \%$ of mothers and $67.6 \%$ newborns received good quality care during intrapartum and immediate postpartum periods respectively. However, only $47.2 \%$ of mothers and newborns received a friendly care during childbirths. The independent predictors of quality intrapartum and newborn care were the appropriate use of partograph (AOR 3.92; 95\% Cl 1.78, 8.63), friendly maternal and newborn care services (AOR 7.9; 95\% Cl 3.59, 17.33), more than two years working experience (AOR $0.31 ; 95 \% \mathrm{Cl} 0.13,0.73$ ) and using services in different Zones in the study area.

Conclusions: The quality intrapartum care is poor in the study area and it is associated with inappropriate use of partograph, unfriendly care, and experience of health providers. Scaling up obstetric service, continuous training and motivation of service providers and revising the criterion for accreditation of service providers are important.

Keywords: Quality, Intrapartum and newborn care, Factors associated, Northern Ethiopia

\section{Background}

Childbirth complications are the most common causes of death among women living in developing countries. The fetus and newborn are also at high risk of death, largely as the result of intrapartum hypoxia (i.e. "Birth asphyxia") [1]. During this period, skilled birth attendants (SBAs) are considered as an effective intervention in improving quality service [2,3]. Consequently, the government of Ethiopia has continued to scale up the number of SBAs and planned to reach to $80-90 \%$ SBAs utilization by 2020 [4]. The assumption is that quality could be improved by increasing the number of SBAs and health facilities.

\footnotetext{
* Correspondence: girmaf4@yahoo.com

${ }^{1}$ Mekelle University, School of Public Health, P.O.BOX: 1871 Mekelle, Ethiopia Full list of author information is available at the end of the article
}

However, little emphasis has been given to the quality of intrapartum care provided by birth attendants.

Failure to provide quality maternal health service may lead to maternal deaths [5], with $99 \%$ of global maternal death occuring in developing countries [6]. Sub-Saharan Africa countries had the highest maternal mortality rate with poor progress in its reduction [6]. Ethiopia is one of the 10 countries with the highest maternal (412/ $100,000)[6,7]$ and neonatal mortality statistics $(37 / 1000$ live births) since $2005[8,9]$.

As consequence of poor quality towards basic obstetric care, $49 \%$ of the total causes of perinatal deaths in Ethiopia were due to obstructed labor [10,11]. Medical errors and poor hospital services are also the most common causes of maternal death in Tigray, where this 
study was conducted [12]. Therefore, a good proportion of pregnant women do not use maternal and childbirth health care services. Failure to utilize the above services by the women could be attributed either their negative attitude on quality or how care is provided [1]. Surprisingly, the health care system in Ethiopia is still in the same status of quality based on standards adopted from the $2003 \mathrm{WHO}$ guidelines [1].

Limited studies have been conducted in Ethiopia on the associated factors and the level of quality intrapartum and newborn care. Very few studies have tried to assess the structural and outcome components of quality of care in African countries [13-16]. Although this study is from the same cohort of the recently published article [17] but the previous article was mainly focused on the overall quality of service delivery at health facility level. This focused on input, process and output quality measurements. However, the published article did not report on how the quality intraprtum and friendly care is given to mothers and newborns by health care providers [17]. Therefore, this study aimed to fill the above gap by assessing the magnitude and factors associated with quality intrapartum and newborn care. In addition the study attempted to explore the perspective of health facilities, service providers and mothers in relation to the quality of the services provided.

\section{Methods}

The study was conducted in three zones of Tigray region, Northern Ethiopia. A facility based cross-sectional study design was used among skilled birth attendants (SBA) and mothers. Mothers with normal labour at the active first stage were observed until the immediate postpartum period. Mothers with complications during labour were excluded from this study.

A total of 106 skilled birth attendants and 216 labouring mothers from 32 health facilities were included in the study. Health facilities providing maternity services from each district were randomly selected. Sample size calculation for labouring mothers was determined by a single proportion of finite population with $95 \%$ confidence interval, marginal error (d) 5\% and by taking 15\% prevalence $(\mathrm{P})$ of non-beneficial practice during childbirth in Ethiopia [18]. Adding 10\% for non-response rate; a total of 216 mothers attending obstetric care were selected for the observation and chart review.

\section{Data collection procedures}

Four types of data collection tools (non participatory observation, structured interview guide, facility audit and record review form) were used to gather data for this study. Non-participatory observation was used to observe mothers and SBAs during childbirth and immediate postpartum periods to assess quality intrapartum care.
Mothers in active labour were observed during day and night time. The data collector stayed in the delivery room without interfering with the care being provided to mothers and newborns. A structured interview guide was used to conduct interviews with SBAs about their experiences and knowledge. Facility audit form was used to interview the head of the facilities about availability of essential equipment, drugs and supplies. A record review form was used to gather data from the mother charts about the completeness of the partograph. In addition to the training given, health professional who has more than two years working experience in the maternity ward were recruited to collect the data.

\section{Measurements}

Quality Intrapartum care:The individual mothers' score was categorized as receiving good quality if they scored $75 \%$ or more of the intrapartum criteria (69 or more of the 92 criteria). Detail of the measurement and tool is found in the recent published article [17]. All items were prepared as YES/NO questions (Attachment 1).

Care during admission, first, second and third stage of labour, and immediate postpartum period: Measured using items adapted from the WHO standards similar to the national guidelines $[1,19]$. This is part of the intrapartum quality care. Mothers were categorized as receiving the standard quality care if they had received 17 or more of the 22 criteria during admission, 23 or more of the 31 criteria during the first stage of labour, 5 or more of the 6 criteria during the second stage of labour, 8 or more of the 10 criteria during the third stage of labour and 17 or more of the 23 criteria during immediate postpartum periods, corresponding to the 75th percentile of the process quality score distribution for all delivered mothers (Additional file 1).

Quality newborn care: was measured using 11 items adopted from the standards similar to the national guidelines $[1,19]$. This is part of the intrapartum quality care. It was coded as 1 if mothers' scores above 7 of the 11 criteria corresponding to 75th percentile and considered as receiving good quality care, otherwise, it was coded 0 (Additional file 1).

Friendly mother and newborn care was measured using 9 items adopted from FIGO [20]. It was coded as 1 if mothers' scores above 6 of the 9 criteria corresponding to 75th percentile and considered as received good friendly care, otherwise, it was coded 0 . This is part of the intrapartum quality care (Additional file 1).

Knowledge of a skilled birth attendant was measured using 17 items adapted from Reproductive Health Response in Conflict (RHRC) Consortium [21] which focused on basic and emergency obstetric care. If SBAs have scored above mean from the total 17 scores, he/she 
will be considered as having good knowledge, otherwise considered as poor (Additional file 2).

Input quality was measured using eight dimensions with a total of 40 items about facility preparedness. Facilities were categorized to be of good quality if it scored 30 or more of the 40 items. Detail of the measurement and tool is found in the recent publication [17].

Misuse of partograph was measured based on the time when skilled birth attendant start to fill partograph during labour and childbirth. Code 1 if skilled birth attendant starts and filled the partograph after birth, otherwise, coded as 0 .

Completeness of partograph: measured using 14 items adopted from a component of a partograph. Completeness was assessed if $>=80 \%$ of the 14 items were filled correctly in the partograph to be classified as a complete partograph ( $>=11$ items out of 14 items), otherwise incomplete (Additional file 2).

\section{Statistical analysis}

Data were analyzed using STATA version 12. Data were summarized by descriptive statistics like frequency distribution, percentage, tables, and graphs. Overall quality intrapartum, newborn care and friendly care were measured by aggregating data using cutoff point of $75 \%$. In measuring quality care, the assumption was taken from a Malawi study [22]. The logistic regression model was used to assess the determinants of quality intrapartum and newborn service. A $p$-value of less than 0.05 was considered as the cutoff point for statistical significance. Hosmer-Lemeshow test was used to compare and rule out the goodness of fit of the models. Multicollinearity was examined, and all covariates having a value of variance inflation factor of 10 were tolerated.

\section{Results}

A total of 106 SBAs and 216 labouring mothers visiting the 32 study health facilities during the study period were agreed to participate in the study. The mean age of the mothers involved in this study was 26.8 (SD \pm 6.2 ) years. Majority of the mothers, 192 (89\%) were married and $77(35.6 \%)$ were unable to read and write. Among the mothers included in this study, 69 (31.9\%) had given birth for the first time and 200 (92.6\%) had ANC follow-up. Most mothers, 148 (68.5\%) used ambulance to reach the health facilities. Most mothers, 153 (70.8\%) gave birth at the health center and 63 (29.2\%) gave birth in hospitals. Of the 106 skilled birth attendants included in this study, 69 (65.1\%) were diploma holder midwives and 80 (75.5\%) were females. The median age and total working experience of attendants were 27 years (IQR: 24-35) and three years (IQR: 1-3), respectively (Table 1$)$.
Table 1 Socio-demographic characteristics of mothers and skilled birth attendants in Northern Ethiopia, 2015

\begin{tabular}{|c|c|c|}
\hline Socio-demographic characteristics & Number & Percentage \\
\hline \multicolumn{3}{|l|}{ A: Mothers characteristics $(n=216)$} \\
\hline \multicolumn{3}{|l|}{ Age $(n=216)$} \\
\hline$<18$ years & 4 & 1.8 \\
\hline $18-23$ years & 71 & 32.9 \\
\hline 24-29 years & 61 & 28.2 \\
\hline $30-35$ years & 60 & 27.8 \\
\hline$>=36$ years & 20 & 9.3 \\
\hline \multicolumn{3}{|l|}{ Marital status } \\
\hline Single & 16 & 7.4 \\
\hline Married & 192 & 89.0 \\
\hline Divorced & 4 & 1.8 \\
\hline Separated & 4 & 1.8 \\
\hline \multicolumn{3}{|l|}{ Educational status } \\
\hline Unable to read and write & 77 & 35.6 \\
\hline Able to read and write & 9 & 4.2 \\
\hline $1-4$ grade & 32 & 14.8 \\
\hline $5-8$ grade & 39 & 18.1 \\
\hline 9-10 grade & 49 & 22.7 \\
\hline $11-12$ grade & 10 & 4.6 \\
\hline \multicolumn{3}{|c|}{ Type of health facility used for delivery service } \\
\hline Health center & 153 & $70.8 \%$ \\
\hline Hospital & 63 & $29.2 \%$ \\
\hline \multicolumn{3}{|c|}{ B: Skilled birth attendants characteristics $(n=106)$} \\
\hline \multicolumn{3}{|l|}{ Profession } \\
\hline Midwife bachelor degree & 34 & 32.1 \\
\hline Midwife diploma & 69 & 65.1 \\
\hline Nurse diploma & 3 & 2.8 \\
\hline \multicolumn{3}{|l|}{ Sex } \\
\hline Male & 26 & 24.5 \\
\hline Female & 80 & 75.5 \\
\hline \multicolumn{3}{|l|}{ Age } \\
\hline Less than 25 years & 31 & 29.3 \\
\hline c25-30 years & 40 & 37.7 \\
\hline c31-36 years & 12 & 11.3 \\
\hline Greater than 36 years & 23 & 21.7 \\
\hline \multicolumn{3}{|l|}{ Working experience } \\
\hline$<=1$ year & 46 & 43.4 \\
\hline $2-4$ years & 42 & 39.6 \\
\hline$>=5$ years & 18 & 17.0 \\
\hline
\end{tabular}

According to the perspective of mothers, the reasons for coming to health facility was reported to being in close proximity to the health facility 24 (11.1\%), difficult labour 54 (25\%), bad birth outcome in pervious birth 4 
(1.9\%), advised by health providers to deliver at health facility $46(21.3 \%)$ and to get quality delivery service 88 (40.7\%).

\section{Quality of intrapartum care}

About 63 (29.2\%, 95 CI: 23.1-35.2) of mothers received good quality intrapartum care. More than half, 146 (67.6\%, 95 CI: 61.1-74.1) of newborns received good quality newborn care during delivery and the immediate postpartum period. One third of mothers got a quality intrapartum care during first-stage of labour 63 (29.2\%) (Fig. 1).

Below half, 102 (47.2\%, CI: 40.3-53.7) of mothers and newborns received friendly care during delivery and the immediate postpartum period. All mothers received maternity service free of charge and $40 \%$ of mothers were allowed to have birth companion (Fig. 2).

\section{Factors associated with the good quality intrapartum service}

After including variables at bivariate regression with $p$-value less than 0.25 into the multivariable logistic regression model; friendly care, appropriate use of partograph, working experience of health personnel and mother using service in different Zones in the study area were significant predictors of a good quality intrapartum and newborn care (Table 2).

\section{Discussion}

The aim of this study was to assess the magnitude and factors associated with quality intrapartum care during childbirth and the immediate postpartum period. Accordingly, only $29.2 \%$ of mothers received good quality intrapartum care. Working experience, friendly maternal and newborn care, appropriate use of partograph, and using service at different Zones of the study area were significant predictors of quality intrapartum care.
In this study, the practice of quality intrapartum care was poor, thus only $29.2 \%$ of mothers received standard services during childbirth. This study result is consistent with studies done in some Sub-Saharan Africa [15, 16, 23], where the intrapartum care was reported to be poor. This finding is lower than the study done in Tanzania (60\%) [24], and higher compared to another study in Tanzania (14\%) [25]. The difference in the findings could be due to difference in measuring the quality care and the study subjects included. However, this study took a composite of variables to measure quality care and involved observations. This finding indicated that there is delay in treatment (if provider do not follow and provide service, according to the standards) which is the most common cause of death to the mother and newborn. Since intrapartum stillbirth and puerperal sepsis are often related to the poor intrapartum care [26].

The quality of newborn care in this study was found to be poor. Only $67.6 \%$ of newborns received standard care, based on the standards. This implies that service providers are neglecting the service to newborns, missing the procedures, or have poor skills to care for newborn. However, our finding is higher compared to the findings of two studies in Ghana which was (33\%) [27] and (42\%) [15] and another study in Ethiopia (18\%) [18]. The difference could be due to the use of different measurement for quality newborn care between studies. In the Ghanaian study, the focus was more on the components of availability of materials for newborn care and emergency newborn care [15].

In the current study, mothers who received friendly care during childbirth were more likely to receive quality intrapartum care; this indicates there are mothers who neither received quality intrapartum nor friendly care during childbirths. The reasons could be due to poor skill and competency of service providers. In addition, inadequate number of skilled providers, high workload,

— of good quality intrapartum practice by service providers

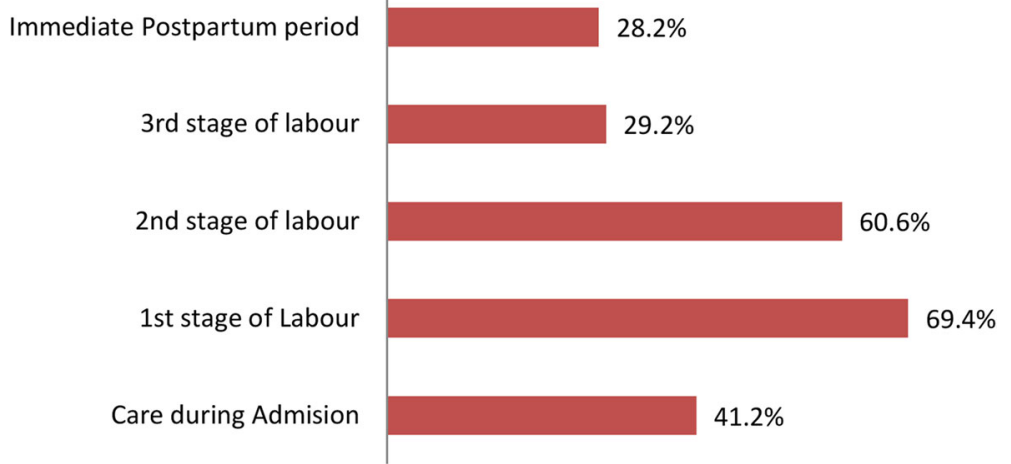

Fig. 1 Intrapartum quality care from admission to immediate postpartum periods to mothers and newborn, Ethiopia, 2015 


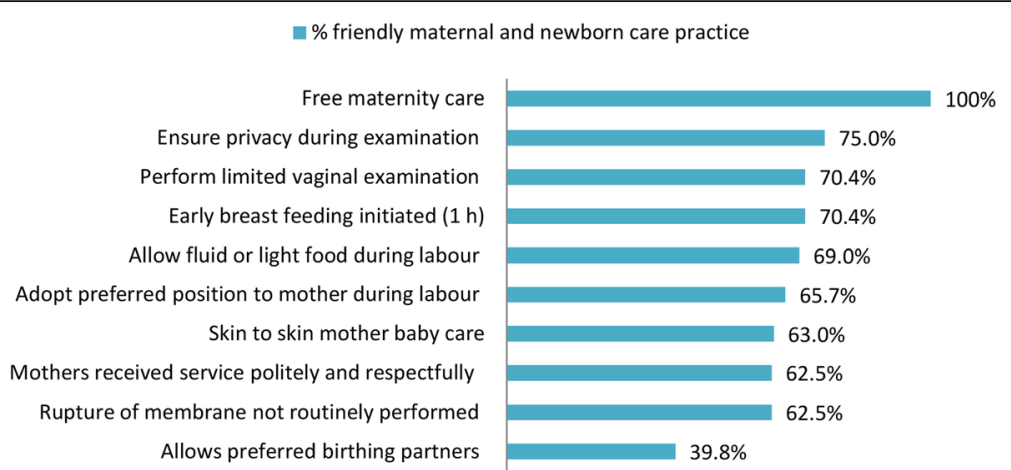

Fig. 2 Friendly mother and newborn care during intrapartum and immediate postpartum period in Northern Ethiopia, 2015

Table 2 Factors associated with good quality intrapartum and newborn care in Northern Ethiopia, 2015

\begin{tabular}{|c|c|c|c|c|}
\hline \multirow[t]{2}{*}{ Variables } & \multicolumn{2}{|c|}{ Quality intrapartum } & \multicolumn{2}{|c|}{ Odd ratio with 95\% Cl } \\
\hline & Good $n(\%)$ & Poor $n(\%)$ & Cured Odd ratio & Adjusted odd ratio \\
\hline \multicolumn{5}{|c|}{ Friendly care during birth } \\
\hline Poor & $14(12.3 \%)$ & $100(87.7 \%)$ & 1 & 1 \\
\hline Good & $49(48.0 \%)$ & $53(52.0 \%)$ & $6.6(3.34-13.05)^{* *}$ & $7.9(3.59-17.33)^{* *}$ \\
\hline \multicolumn{5}{|c|}{ Misuse of partograph by health providers } \\
\hline Yes & $17(16.0 \%)$ & $89(84.0 \%)$ & 1 & 1 \\
\hline No & $46(41.8 \%)$ & $64(58.2 \%)$ & $3.76(1.98-7.15)^{* *}$ & $3.92(1.78-8.63)^{* *}$ \\
\hline \multicolumn{5}{|c|}{ Service providers working experience } \\
\hline$<1$ Year & $25(36.8 \%)$ & $43(63.2 \%)$ & 1 & 1 \\
\hline$>=2$ Years & $38(25.7 \%)$ & $110(74.3 \%)$ & $0.59(0.32-1.1)$ & $0.31(0.13-0.73)^{*}$ \\
\hline \multicolumn{5}{|l|}{ Zone } \\
\hline East & $22(20.4 \%)$ & $86(79.6 \%)$ & 1 & 1 \\
\hline South east & $24(51.1 \%)$ & 23(48.9\%) & $4.08(1.95-8.54)^{* *}$ & $6.2(2.36-16.28)^{* *}$ \\
\hline South & $17(27.9 \%)$ & $44(72.1 \%)$ & $1.5(0.73-3.13)$ & $1.7(0.64-4.50)$ \\
\hline \multicolumn{5}{|c|}{ Type of health facility care given } \\
\hline Health center & $49(32.0 \%)$ & $104(68.0 \%)$ & 1 & 1 \\
\hline Hospital & $14(22.2 \%)$ & $49(77.8 \%)$ & $0.61(0.31-1.2)$ & $0.54(0.21-1.41)$ \\
\hline \multicolumn{5}{|c|}{ Sex of Health provider who provide care } \\
\hline Male & $17(34.0 \%)$ & $33(66.0 \%)$ & 1 & 1 \\
\hline Female & $46(27.7 \%)$ & $120(72.3 \%)$ & $0.74(0.38-1.46)$ & $1.34(0.56-3.24)$ \\
\hline \multicolumn{5}{|c|}{ Knowledge of service providers on obstetric and newborn care } \\
\hline Good & $26(26.3 \%)$ & $73(73.7 \%)$ & 1 & 1 \\
\hline Poor & $37(31.6 \%)$ & $80(68.4 \%)$ & $1.3(0.72-2.35)$ & $1.91(0.87-4.19)$ \\
\hline \multicolumn{5}{|c|}{ Health facility input quality (readiness) } \\
\hline Good & $45(25.6 \%)$ & $131(74.4 \%)$ & 1 & 1 \\
\hline Poor & $18(45.0 \%)$ & $22(55.0 \%)$ & $2.38(1.17-4.84)^{*}$ & $1.48(0.55-3.94)$ \\
\hline \multicolumn{5}{|c|}{ Mode of current birth } \\
\hline SVD & $56(27.9 \%)$ & $145(72.1 \%)$ & 1 & 1 \\
\hline Instrumental & $7(46.7 \%)$ & $8(53.3 \%)$ & $2.27(0.78-6.54)$ & $1.25(0.33-4.79)$ \\
\hline
\end{tabular}

* Significant variable ( $p$-value $<0.05)$, ** significant variable $(p$-value $<0.001)$, SVD: spontaneous vaginal delivery 
and poor job satisfaction could be other reasons for the poor service $[12,14,16]$. The result of this study is consistent with studies in developing countries in which friendly service to mother during childbirth is poor [28, 29]. This may influence future maternal health service utilizations (antenatal, delivery and postnatal), and reduction of maternal and newborn mortalities.

Misuse of partograph during childbirth was one of the problems identified in this study. Those service providers who used and filled partograph appropriately were more likely to practice quality intrapartum care than those who misused. This indicated poor attitude, knowledge and skills on how to fill partograph among service providers. Similar problem was reported in Ethiopia [18]. This finding is consistent with studies in Africa, where the misuse of the partograph is common [15]. Not using or misusing of partograph can delay treatment in case of prolonged labour which leads to obstructed labour, ruptured uterus, bleeding, fetal death and infection to mothers and newborns [18].

In the current study, there was a significant difference in the quality of intrapartum care given in the three Zones. This difference could be due to the improper allocation of resources like mal-distribution of human resources, opportunity in training or involvement of non-governmental organizations in the three Zones. Coordination and monitoring by the local regional health bureau could improve the equitable distribution of resource between the Zones.

In this study, having more than two years working experience at maternity service was less likely associated with good quality intrapartum care. This indicates, whether a service providers work for many years or not, they are not improving their practice, this could be due to the lack of opportunity for appropriate training. This is supported by another study in sub-Saharan Africa where obstetric experience showed a non-linear relationship with knowledge and skills [30]. Refresher trainings and reform in human resource management is critical in order to improve skills and competency of health professionals in health facilities. It is also important to allocate adequate budget for training and for continuous professional career development.

Quality intrapartum care was not significantly associated with quality care services from health center or hospital. This indicates that childbirth care was provided poorly in both hospitals and health centers. Compared to periphery areas (health centers), the service given at hospitals is expected to be different and better in terms of quality cares due to the availability of experienced and high level human power, resource and supplies. However, in the current study, there is no difference between the care given in hospitals and health centers. This could be due to high workload of service providers as a result of high case follow at hospitals. So, it is important to give attention to the care given in hospitals.

As a limitation of this study, there may be observer bias between data collectors and Hawthorne effect. But during the lengthy period of observation, it is difficult for the health care personnel maintain their artificial standards of behavior during the long period of observation, and therefore any behavior change will be likely to persist during childbirth [31]. To reduce this effect, we tried to exclude the first observation from each skilled attendant. In addition, we recruited experienced skilled birth attendants, given intensive training and standardization of instrument prior to data collection and continuous supervision during data collection were done. The small sample size could also have an effect on the association between dependent and independent variables. This was due to the small case flow of mother's in the study area, especially in rural health centers. Therefore, those limitations can under or over estimate the associations. Hence, it is better to consider those limitations while interpreting these findings.

This study did not relate the outcome variable (quality intrapartum care) with the morbidity and mortality during childbirth since most of the study areas were in rural health facilities. Many mothers in those facilities were immediately referred to higher institutions, in case of even minor complications, so it was difficult to follow these mothers till the end and difficult to see the birth outcome. Besides this, in case of the complications, the health providers use different standards in managing the complications and did not follow the usual guideline or checklist for normal birth. Therefore, to reduce this mix up in population (mother with normal labour and with complications), we only followed mothers with normal labour. Even after recruiting, we excluded the mothers with complications whatever the causes because it was difficult to follow the mothers in the same directions and using the same checklist. But, it is possible to relate quality intrapartum care with morbidity or mortality in hospital based research since it is less likely to refer the mothers to another facility. So, we recommend considering this in future studies conducted in hospitals.

\section{Conclusions}

Quality intrapartum and newborn care is below the standard. Working experience among service providers, friendly maternal and newborn care, and appropriate use of partograph were the predictors of quality intrapartum and newborn care. Using service in hospital or health center was not associated with quality intrapartum and newborn care. The care given was also different in the three zones of the study areas. This shows there is poor adherence to standards, imbalance in qualified service providers, equipments and supplies in the three Zones. 
Therefore, renewing licenses, providing refresher training and on-site mentoring to service providers, staff motivation mechanism for overloaded skilled providers are essential. Giving emphasis to the quality care of the mother and newborn during childbirths at each level of health facility is also very important.

\section{Additional files}

Additional file 1: List of variables used in measuring stages of intrapartum quality service, quality of newborn care, and friendly mother and newborn care in Northern Ethiopia. (PDF 637 kb)

Additional file 2: List of variables used in measuring knowledge of skilled birth attendant and completeness of partograph in Northern Ethiopia. (PDF $559 \mathrm{~kb}$ )

\section{Abbreviations}

FIGO: International Federation of Gynecology and Obstetrics; SBAs: Skilled birth attendants; SVD: spontaneous vaginal delivery

\section{Acknowledgements}

Our heartfelt thanks go to Mekelle University and Addis Continental Institute of Public Health for all round support. We thank the African Population and Health Research Center for offering the African Doctoral Dissertation Research Fellowships with financial and technical support. We extend our deepest gratitude to the Tigray Regional Health Bureau, the health facilities managers and skilled birth attendants for their facilitation to carry out the study. Last but not least we thank the study participants who shared their priceless time, and the data collectors for their full commitment during the entire period of the study.

\section{Ethical approval and consent to participate}

The study was approved by Mekelle University Institutional Review Board (ERC0427 /2014) and a formal letter of permission was obtained from the Tigray Regional Health Bureau. Informed verbal consent was obtained from each mother and skilled birth attendant for observation, access to medical record and interview. In this study, there were four adolescent mothers less than 18 years of age. For those mothers, we did not take additional consent from the parent or legal guardian, since our study was simple observation about the care given to the mothers and has no invasive procedure. Our ethical guideline also allows us to take only consent from adolescent mothers above the age of 15 in case of non-invasive and insensitive studies.

\section{Funding}

This research received funding and technical support from Mekelle University and Addis Continental Institute of Public Health as a postgraduate student project and partially supported through a PhD fellowship (sub-award grant) by the African Population and Health Research Center for the African Doctoral Dissertation Research Fellowships with grant number ADF005. The funding bodies had no contribution in the design of the study and collection, analysis, and interpretation of data and in writing the manuscript.

\section{Availability of data and materials}

The raw datasets used during the current study are available from the corresponding author on reasonable request.

\section{Authors' contributions}

GF, YB and AW conceived and designed the study, performed analysis and interpretation of data and critically reviewed the manuscript. All authors read and approved the final manuscript.

\section{Consent for publication}

Not applicable.

\section{Competing interests}

The authors declare that they have no competing interests.

\section{Publisher's Note}

Springer Nature remains neutral with regard to jurisdictional claims in published maps and institutional affiliations.

\section{Author details}

${ }^{1}$ Mekelle University, School of Public Health, P.O.BOX: 1871 Mekelle, Ethiopia.

${ }^{2}$ Addis Continental Institute of Public Health, Addis Ababa, Ethiopia. ${ }^{3}$ Addis

Ababa University, School of Public Health, Addis Ababa, Ethiopia.

Received: 13 February 2018 Accepted: 8 January 2019

Published online: 18 January 2019

\section{References}

1. World Health Organization (WHO), Safe motherhood, Care in Normal birth: A practical guide. 1996, WHO: Geneva, Switzerland Available: http://www. midwiferyservices.org/care_in_normal_birth_practical_guide.pdf. Accessed 7 July 2014.

2. Hulton LA, Matthews Z, Stones RW. A framework for the evaluation of care in maternity services: the question should not be why do women not accept the service that we offer, but why do we not offer a service that women will accept? 2000, University of Southampton and Opportunity and Choice. Available: https://eprints.soton.ac.uk/40965/1/12757_Matthews.pdf. Accessed 16 Dec 2015.

3. World Health Organization (WHO). Mother-baby Package: implementing Safe motherhood in countries, Geneva, WHO. 1996. Available from: http:// apps.who.int/iris/bitstream/handle/10665/63268/WHO_FHE_MSM_94.11_ Rev.1.pdf?sequence=1. Accessed 14 Dec 2015 .

4. Federal Democratic Republic of Ethiopia Ministry of Health (FDRE MOH) Health Sector Transformation Plan (HSTP) from 2015/16 up to 2019/20, Draft_V1. May 2014. Available from: https://www.globalfinancingfacility.org/ sites/gff_new/files/Ethiopia-health-system-transformation-plan.pdf . Accessed 27 Apr 2017

5. Fawole $\mathrm{AO}$, Okunlola MA, Adekunle AO. Clients' perceptions of the quality of antenatal care. J Natl Med Assoc. 2008;100(9):1052-8 PMID:18807434.

6. WHO, UNICEF, UNFPA, World Bank Group and the United Nations Population Division. Trends in Maternal Mortality: 1990 to 2015. 2015, World Health Organization: Geneva, Switzerland Available from: https://www.who. int/reproductivehealth/publications/monitoring/maternal-mortality-2015/en/ Accessed 2 Nov 2016.

7. Central Statistical Agency (CSA) [Ethiopia] and ICF. Ethiopia Demographic and Health Survey 2016: Key Indicators Report. 2016: Addis Ababa, Ethiopia and Rockville, Maryland, USA, CSA and ICF. Available from: https:// dhsprogram.com/pubs/pdf/FR328/FR328.pdf. Accessed 25 Apr 2017.

8. Central Statistics Agency (CSA). Ethiopian demographic and health survey Addis Ababa: CSA, ORC Macro, 2005. Available from: https://dhsprogram. com/pubs/pdf/FR179/FR179[23June2011].pdf. Accessed 3 Mar 2017.

9. Central Statistics Agency (CSA), and ICF Macro Calverton. Ethiopia demographic and health survey 2011. Addis Ababa: CSA; 2011. Available: https://dhsprogram.com/pubs/pdf/FR255/FR255.pdf. Accessed 3 Mar 2017.

10. Berhan $Y$, Abdela A. Emergency obstetric performance with emphasis on operative delivery outcome: does it reflect the quality of care? Ethiop J Health Dev. 2004;18(2):96-106 Available: https://doi.org/10.4314/ejhd.v18i2. 9944. Accessed 22 Jun 2014

11. Gessessew A, Mesfin M. Obstructed labour in Adigrat zonal hospital, Tigray region. Ethiopia Ethiop J Health Dev. 2003;17(3):175-80 Available: http:// citeseerx.ist.psu.edu/viewdoc/download?doi=10.1.1.609.169\&rep= rep1\&type=pdf. Accessed 24 Jun 2014.

12. Hailu S, Enqueselassie $F$, Berhane $Y$. Health facility-based maternal death audit in Tigray, Ethiopia Ethiopia J Health Dev 2009;23(2):115-119. Available: https://www.researchgate.net/publication/228764067_Health_facility-based_ maternal_death_audit_in_Tigray_Ethiopia. Accessed 17 Jun 2014

13. Tayelgn A, Zegeye DT, Kebede Y. Mothers' satisfaction with referral hospital delivery service in Amhara Region, Ethiopia. BMC Pregnancy Childbirth. 2011;11(78). https://doi.org/10.1186/1471-2393-11-78 PMCID: PMC3254067.

14. Wako G, Berhane Y. Structural quality of reproductive health services in south-Central Ethiopia. Ethiop J Health Dev 2000;14:317-325. Available: https://doi.org/10.4314/ejhd.v14i3.9905. Accessed 21 Feb 2015.

15. Nesbitt RC, Lohela TJ, Manu A, Vesel L, Okyere E, Edmond K, Owusu-Agyei S, Kirkwood BR, Gabrysch S. Quality along the continuum: a health facility assessment of intrapartum and postnatal care in Ghana. PLOS ONE. 2013; 
8(11):e81089. https://doi.org/10.1371/journal.pone.0081089 PMID:24312265 PMCID: PMC3842335.

16. Thérèse $D$, Odile A-T, Valérie G-K, Patrice B, Simon C, Carine R. Quality of normal delivery care in Côte d'Ivoire. Afr Santé Reprod. 2007;11(1):22-32 PMID: 17982945

17. Fisseha G, Berhane Y, Worku A and Terefe W. Quality of the delivery services in health facilities in Northern Ethiopia. BMC Health Serv Res 2017. 17: $p$ 187. Research (2017) 17:187. https://doi.org/10.1186/s12913-017-2125-3. PMCID: PMC5345168.

18. Getachew A, Ricca J, Cantor D, Rawlins B, Rosen H, Tekleberhan A, et al. Quality of Care for Prevention and Management of Common Maternal and Newborn Complications: A Study of Ethiopia's Hospitals, 2011, Maternal and Child Health Integrated Program (MCHIP) and USAID: Jhpiego Brown's Wharf, 1615 Thames Street, Baltimore, Maryland 21231-3492, USA. Available: https://www.mchip.net/sites/default/files/Ethiopia_QoC_formatted_final.pdf.

19. Sholkamy H, Hassanein N, Cherine M, Elnoury A, Breebaart M and Khalil K. An Observation Checklist for Facility-Based Normal Labor and Delivery Practices: The Galaa Study. 2003, Reproductive health working group HOUSED at the population council regional office for West Asia and North Africa, Egypt. Available: http://citeseerx.ist.psu.edu/viewdoc/download?doi= 10.1.1.175.9269\&rep=rep1\&type=pdf. Accessed 7 Oct 2014.

20. International Federation of Gynecology and Obstetrics (FIGO), International Confederation of Midwives (ICM), White Ribbon Alliance (WRA), International Pediatric Association (IPA) and World Health Organization (WHO). Mother-baby friendly birthing facilities: FIGO Guidelines. International Journal of Gynecology and Obstetrics. 2015; 128:95-99. Available: https://doi.org/10.1016/j.jggo.2014.10.013

21. The Reproductive Health Response in Conflict (RHRC) Consortium. Field - friendly guide to Integrated Emergency Obstetric care in Humanitarian Programs. July 2005, Reproductive Health Response in Conflict Consortium, New York, United States of America. Available: https:/www.womensrefugeecommission.org/ resources/document/145-field-friendly-guide-to-integrate-emergency-obstetriccare-in-humanitarian-programs. Accessed 8 Oct 2014.

22. Leslie $H H$, Fink $G$, Nsona $H$, Kruk ME. Obstetric facility quality and newborn mortality in Malawi: a cross-sectional study. PLoS Med. 2016;13(10): e1002151. https://doi.org/10.1371/journal.pmed.1002151.

23. Kigenyi O, Tefera GB, Nabiwemba E, Orach CG. Quality of intrapartum care at Mulago national referral hospital, Uganda: clients' perspective. BMC Pregnancy Childbirth. 2013;13:162. https://doi.org/10.1186/1471-2393-13-162 PMCID: PMC3751160.

24. Nyamtema AS, de Jong AB, Urassa DP, Roosmalen JV. Using audit to enhance quality of maternity care in resource limited countries: lessons learnt from rural Tanzania. BMC Pregnancy Childbirth. 2011;11(94). https:// doi.org/10.1186/1471-2393-11-94 PMCID: PMC3226647.

25. Larson E, Hermosilla S, Kimweri A, Mbaruku GM, Kruk ME. Determinants of perceived quality of obstetric care in rural Tanzania: a cross-sectional study. BMC Health Serv Res. 2014;14:483. https://doi.org/10.1186/1472-6963-14-483 PMCID: PMC4283093.

26. AMDD, UNFPA, UNICEF and WHO. Monitoring emergency obstetric care: A hand book. Geneva: WHO; 2010. Available: https:/www.who.int/reproductivehealth/ publications/monitoring/9789241547734/en/. Accessed 10 Oct 2014

27. Vesel L, Manu A, Lohela TJ, Gabrysch S, Okyere E, Ten Asbroek AH, et al. Quality of newborn care: a health facility assessment in rural Ghana using survey, vignette and surveillance data. BMJ Open. 2013;3:e002326. https:// doi.org/10.1136/bmjopen-2012-002326 PMCID: PMC3842335.

28. Freedman LP, Kruk ME. Disrespect and abuse of women in childbirth: challenging the global quality and accountability agendas. Lancet. 2014; 384(9948):e42-4. https://doi.org/10.1016/S0140-6736(14)60859-X PMID: 24965825.

29. King R, Jackson R, Dietsch E, Hailemariam A. Barriers and facilitators to accessing skilled birth attendants in Afar region. Ethiopia Midwifery. 2015; 31(5):540-6. https://doi.org/10.1016/j.midw.2015.02.004 PMID:24965825.

30. Ameh CA, Kerr R, Madaj B, Mdegela M, Kana T, Jones S, et al. Knowledge and skills of healthcare providers in sub-Saharan Africa and Asia before and after competency-based training in emergency obstetric and early newborn care. PLoS One. 2016;11(12):e0167270.

31. Pittrof R and Campbell O. Quality of Maternity care: Silver Bullet or Red Herring? Dec 2000: Maternal health Programme, Department of Infectious and Tropical Diseases, London School of Hygiene and Tropical Medicine. Available: https:// assets.publishing.service.gov.uk/media/57a08d81e5274a27b20018ad/ HpregQoMCSilverBulletorRedHerring.pdf. Accessed 16 May 2014.

\section{Ready to submit your research? Choose BMC and benefit from:}

- fast, convenient online submission

- thorough peer review by experienced researchers in your field

- rapid publication on acceptance

- support for research data, including large and complex data types

- gold Open Access which fosters wider collaboration and increased citations

- maximum visibility for your research: over $100 \mathrm{M}$ website views per year

At BMC, research is always in progress.

Learn more biomedcentral.com/submissions 